\title{
Measurement of Emissions from Passenger-Picking-up Vehicles at Airport Terminals
}

\author{
Fengxiang Qiao, Larry Hill, Xiaobing Wang and Lei Yu \\ Innovative Transportation Research Institute, Texas Southern University, Houston 77004, USA
}

\begin{abstract}
Rather than parking at nearby hourly parking lots, many passenger-picking-up vehicles prefer to idle at terminals and/or drive cycling around terminal facilities. As a result, extra vehicle emissions may be produced in an airport area. Even though there are limited studies on such emissions at airports, these estimations were normally based on the date emission models, which might cause bias in emission estimations. This paper proposes an approach to employ the floating car method and Global Positioning System (GPS) to record speeds and acceleration rates of idling and cycling vehicles at airport terminals. The tests were conducted under different time periods and traffic demands with different waiting time. The speeds and acceleration rates are synthesized to yield Vehicle Specific Power's (VSP) and Operational Mode (OM) distributions. Utilizing the Environmental Protection Agency (EPA) emission estimation model Motor Vehicle Emission Simulator (MOVES), pollutants and green house gas emission indexes (e.g. $\mathrm{NO}_{\mathrm{x}}, \mathrm{CO}, \mathrm{CO}_{2}$ and $\mathrm{HC}$ ) and fuel consumptions can be easily estimated. As an illustration of the proposed approach, the research team collected GPS data at a terminal in Houston William Hobby Airport (HOU), and calculated the VSP distributions and OM distributions. Emissions of passenger-picking-up vehicles around these congested airport terminals.
\end{abstract}

Key words: Vehicle emissions, passenger-picking-up vehicle, terminals, airport, vehicle specific power, operational mode distribution.

\section{Introduction}

Many efforts have been made to enhance the safety and mobility on roads by developing wireless communication systems [1-3]. Meanwhile, the developed systems have successfully mitigated the mass vehicle emissions, mostly at work zones, stop sign intersections and signalized intersections [4-8]. However, little attention has been paid on the emissions within the terminals in an airport. In fact, in today's modernized society, people tend to look for the fastest way to travel to certain destinations around the world and even locally. Airplanes are the fastest and the most logical alternative to get to destinations. However, more than usual vehicle emissions may be produced in the terminals of an airport, which are mostly attributed by congestion and airport internal management styles. What's more, it has been demonstrated that vehicle emissions are highly

Corresponding author: Fengxiang Qiao, associate Ph.D., main research fields: transportation and vehicle emissions. associated public health $[9,10]$. During this relative research, people should have the biggest concern and evaluated this problem early since this will eventually pose a higher risk of health to peoples nearby the terminals, and even contribute significantly to climate changes in a global scale $[11,12]$. Alternative strategies should be implemented to extricate and eliminate or at least reduce the emissions at these airport terminals.

The errors of estimated mobile source emissions in the planning process around the airports are unavoidable. A need may therefore exist to develop a systematic approach to analyzing airport related traffic that could be useful to mobile-source emission estimation [13]. There is a unique pattern on traffic and vehicle activities in airports, such as driving behavior, speed distribution, parking activity, curbside activity and more frequent acceleration/deceleration. Each driver has a certain way to handle the driving conditions.

In practice, current urban transportation planning process does not address the traffic and emission 
problems around the terminals in an airport appropriately. The airport is simply treated as a special generator in the overall travel demand forecasting and the emissions estimation. Travel demands to and from the airports are forecasted based on the traditional four-step sequential. This type of modeling practice is unable to capture the unique driving behaviors, parking and curbside traffic activities at the airport. The errors of estimated mobile source emissions in the planning process around the airports are unavoidable.

A need may therefore exist to develop a systematic approach to analyzing airport related traffic that can and will be very useful to mobile-source emission estimations. In the study, emission factors are generated from the emission factor model MOBILE, which virtually reflects the average urban highway driving conditions [13].

Before the release of EPA approved emission model MOVES in recent years, the MOBILE emission factor model was widely used for area-wide urban transportation planning process. It is unknown whether it is also applicable to airport related emission estimations. There are many on-going research efforts worldwide in developing micro scale mobile source emission models, which bring hopes for possible applications to airport related emission analysis.

Many researchers have developed numerous microscopic levels emission models, which can account for acceleration and deceleration, and compute vehicle emissions on a second by second basis $[14,15]$. One of such models being widely used is the Comprehensive Modal Emission Model (CMEM) [16]. The CMEM can be used to perform a microscopic level emission analysis for a specific area, such as the airport [13]. The validation of the traffic simulation is to judge whether the simulated results match with the field observations within an acceptable range. In using these microscopic simulation models, some parameters should be calibrated such as traffic volume, average travel time, average travel speed, freeway density, queue length, etc..
Properly estimation emission at airport terminals is very important. Very few studies have been focused on terminal emissions, which are however based on old emission estimation models. With the EPA new emission model MOVES, which is based on real world testing database, the ways of data collection and estimation should both be updated. MOVES emission estimation can be simply based on the collection of vehicle speed and acceleration rates, which can be easily converted into the VSP and operation mode distributions. This information can be used to either update the MOVES database, or check with other real world emission database for the estimation of terminal emissions.

This paper proposes an approach to employ the floating car method and GPS to record down speeds and acceleration rates of idling and cycling vehicles at terminals under different situations, so as to estimation emissions at airport terminals.

\section{Test Plan and Materials}

There are two parts of tests. The first part is a questionnaire survey. One hundred random peoples were asked on their driving habits when picking up friends at terminals. The second part is to use the floating car method to follow the operations of passenger-pick-up vehicles at an airport terminal. GPS device recorded the instant speeds and acceleration rates of vehicles for the estimation of terminal emissions later on.

\section{Results and Discussion}

\subsection{Questionnaire Survey}

For the first part of survey, one hundred peoples were surveyed on their preferences when picking up passengers at terminals. The very important information from this survey is the average cycling time that test subjects normally spend at terminals. This is illustrated in Fig. 1.

From Fig. 1, it is seen that most people cycling at terminals in either less than 30 minutes $(36 \%)$ or more 


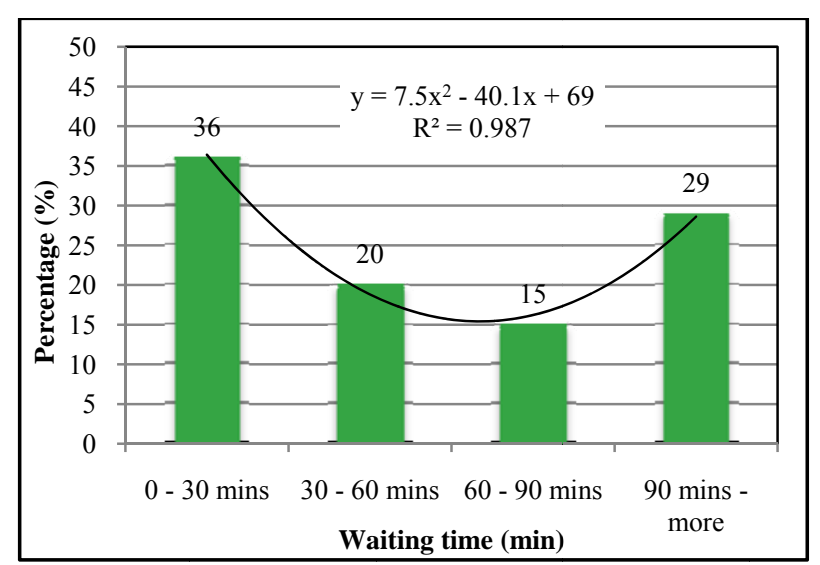

Fig. 1 Waiting time at terminals when picking up friends.

than 90 minutes (29\%). About 56\% stays around the terminal less than 1 hour. This implies that if there is a "One Hour Free" policy, emissions from this big portion could be eliminated.

\subsection{Floating Car Test}

This test was conducted on February 24, 2013 terminal $\mathrm{C}$ in zone 3 of William P. Hobby airport in city of Houston. The test vehicle followed other cycling vehicles at the terminal along two different driving patterns (peak and non-peak hours) with GPS device recoding the geo-location data for every second. The non-peak hours were from 12-2:30 pm, and the peak hours were from 3:30-5:30 pm. Fig. 2 shows the leading vehicles in front of the test vehicle along the cycling route, while Fig. 3 is the plaque listing parking rates in a nearby hourly parking lot. The driving paths of test vehicle are illustrated in Fig. 4.

\subsection{Vehicle Emissions}

The recorded geo-location information from GPS devices was retrieved for speed and acceleration rates calculation. Based on the binning standard of the EPA's new emission estimation model MOVES in Table 1, the VSP distribution and the associated emission rates in the operating mode 30 bins were classified. The information of the test vehicle is listed below.

- Modal: Nissan Altima;

- Year: 1999;

- Mileage: 80,000 mile.

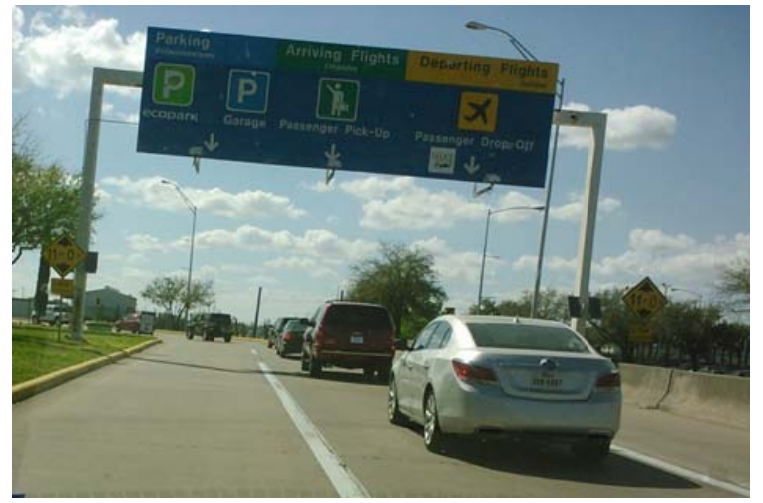

Fig. 2 The leading vehicles in front of the test vehicle cycling a terminal at William P. Hobby airport, Houston, TX.

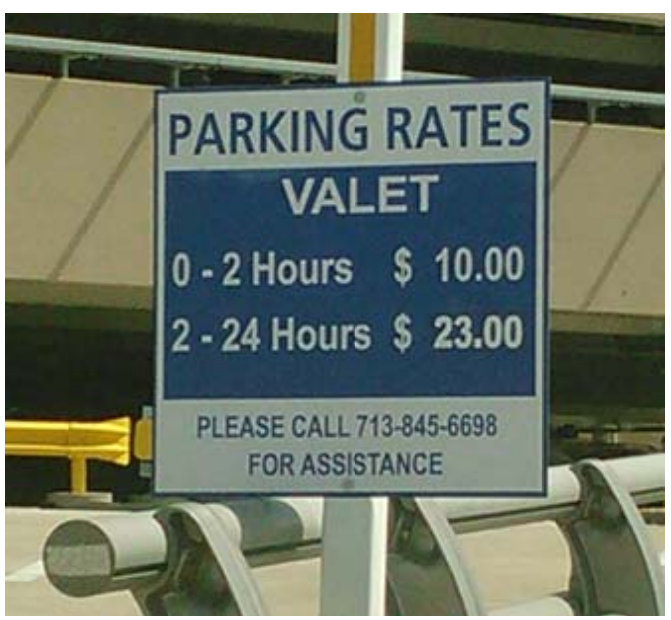

Fig. 3 The parking rates at an hourly parking lot of William P. Hobby airport, Houston, TX.

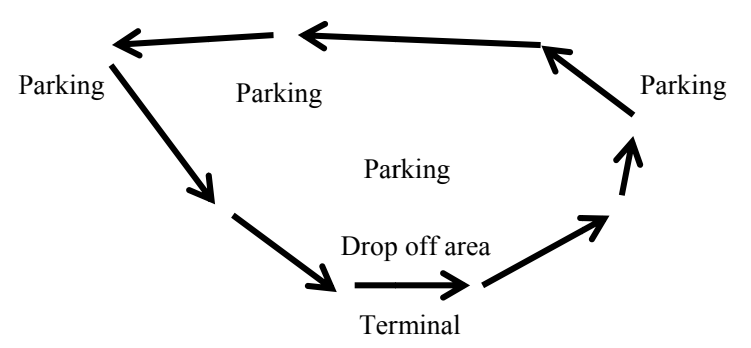

Fig. 4 Driving path at a terminal of William P. Hobby airport, Houston, TX.

The emission rates in this research were estimated, based on an emission database that were prepared by a number of on-board emissions tests using a Portable Emission Measurement System (PEMS). The operating mode ID and emission rates used for emission calculation are listed in Table 1.

Fig. 5 illustrates the difference in the calculated hourly emission rates in the terminal and the previous 
Table 1 Operating mode ID and emission rates [17].

\begin{tabular}{|c|c|c|c|c|c|c|}
\hline $\begin{array}{l}\text { Operating } \\
\text { mode ID }\end{array}$ & Operating mode name & $\begin{array}{l}\text { Frequency } \\
(\%)\end{array}$ & $\mathrm{CO}_{2}(\mathrm{~g} / \mathrm{s})$ & $\mathrm{CO}(\mathrm{mg} / \mathrm{s})$ & $\mathrm{HC}(\mathrm{mg} / \mathrm{s})$ & $\mathrm{NO}_{\mathrm{x}}(\mathrm{mg} / \mathrm{s})$ \\
\hline 0 & $\begin{array}{l}\text { Braking: } \\
\text { Acceleration }<-2 \mathrm{mph} / \mathrm{s} \text {, } \\
\text { or }<-1 \mathrm{mph} / \mathrm{s} \text { for } 3 \text { consecutive seconds }\end{array}$ & 0.416393 & 0.919917 & 1.487536 & 0.367345 & 1.044941 \\
\hline 1 & Idling: $-1 \leq$ speed $<1$ & 22.003068 & 0.819847 & 0.393507 & 0.267676 & 2.141207 \\
\hline 11 & $\begin{array}{l}\text { Low speed coasting: } \\
\text { VSP }<0,1 \leq \text { speed }<25\end{array}$ & 20.173132 & 1.175464 & 3.233798 & 0.987479 & 1.155647 \\
\hline 12 & $\begin{array}{l}\text { Cruise/Acceleration: } \\
0 \leq \mathrm{VSP}<3,1 \leq \text { speed }<25\end{array}$ & 32.818321 & 1.790468 & 5.660321 & 1.243497 & 2.076512 \\
\hline 13 & $\begin{array}{l}\text { Cruise/Acceleration: } \\
3 \leq \mathrm{VSP}<6,1 \leq \text { speed }<25\end{array}$ & 7.254 & 3.014824 & 7.76362 & 1.605278 & 2.92462 \\
\hline 14 & $\begin{array}{l}\text { Cruise/Acceleration: } \\
6 \leq \mathrm{VSP}<9,1 \leq \text { speed }<25\end{array}$ & 4.1968 & 4.094227 & 6.934645 & 1.560997 & 4.633115 \\
\hline 15 & $\begin{array}{l}\text { Cruise/Acceleration: } \\
9 \leq \mathrm{VSP}<12,1 \leq \text { Speed }<25\end{array}$ & 2.892834 & 4.832245 & 8.338537 & 2.021707 & 6.973868 \\
\hline 16 & $\begin{array}{l}\text { Cruise/Acceleration: } \\
12 \leq \text { VSP, } 1 \leq \text { speed }<25\end{array}$ & 4.394039 & 5.076952 & 8.624111 & 2.088111 & 11.948889 \\
\hline 21 & $\begin{array}{l}\text { Moderate speed coasting: } \\
\text { VSP }<0,25 \leq \text { speed }<50\end{array}$ & 1.008109 & 1.270065 & 4.522635 & 0.866627 & 0.763174 \\
\hline 22 & $\begin{array}{l}\text { Cruise/Acceleration: } \\
0 \leq \mathrm{VSP}<3,25 \leq \text { speed }<50\end{array}$ & 0.361604 & 1.853479 & 4.782885 & 1.256803 & 0.975984 \\
\hline 23 & $\begin{array}{l}\text { Cruise/Acceleration: } \\
3 \leq \mathrm{VSP}<6,25 \leq \text { speed }<50\end{array}$ & 0.372562 & 2.885862 & 13.042658 & 2.352288 & 1.900087 \\
\hline 24 & $\begin{array}{l}\text { Cruise/Acceleration: } \\
6 \leq \mathrm{VSP}<9,25 \leq \text { speed }<50\end{array}$ & 0.657462 & 3.369477 & 7.837228 & 1.980389 & 2.870155 \\
\hline 25 & $\begin{array}{l}\text { Cruise/Acceleration: } \\
9 \leq \mathrm{VSP}<12,25 \leq \text { Speed }<50\end{array}$ & 0.558843 & 4.141253 & 17.379759 & 3.429588 & 5.018007 \\
\hline 27 & $\begin{array}{l}\text { Cruise/Acceleration: } \\
12 \leq \mathrm{VSP}<18,25 \leq \text { speed }<50\end{array}$ & 1.227263 & 4.980276 & 11.994299 & 2.628869 & 8.560814 \\
\hline 28 & $\begin{array}{l}\text { Cruise/Acceleration: } \\
18 \leq \mathrm{VSP}<24,25 \leq \text { speed }<50\end{array}$ & 0.777997 & 6.124917 & 17.021034 & 4.126897 & 15.96069 \\
\hline 29 & $\begin{array}{l}\text { Cruise/Acceleration: } \\
24 \leq \mathrm{VSP}<30,25 \leq \text { speed }<50\end{array}$ & 0.493097 & 5.3957 & 80.1975 & 19.0225 & 10.715 \\
\hline 30 & $\begin{array}{l}\text { Cruise/Acceleration: } \\
30 \leq \mathrm{VSP}, 25 \leq \text { speed }<50\end{array}$ & 0.394477 & 3.700133 & 3.153333 & 0.896667 & 5.52 \\
\hline 33 & $\begin{array}{l}\text { Cruise/Acceleration: } \\
\operatorname{VSP}<6,50 \leq \text { speed }\end{array}$ & 0 & 3.435962 & 4.941839 & 1.08801 & 2.731965 \\
\hline 35 & $\begin{array}{l}\text { Cruise/Acceleration: } \\
6 \leq \mathrm{VSP}<12,50 \leq \text { speed }\end{array}$ & 0 & 4.529078 & 5.790972 & 1.450433 & 3.744169 \\
\hline 37 & $\begin{array}{l}\text { Cruise/Acceleration: } \\
12 \leq \mathrm{VSP}<18,50 \leq \text { speed }\end{array}$ & 0 & 5.077762 & 6.476736 & 1.678218 & 5.565324 \\
\hline 38 & $\begin{array}{l}\text { Cruise/Acceleration: } \\
18 \leq \mathrm{VSP}<24,50 \leq \text { speed }\end{array}$ & 0 & 5.439107 & 5.927131 & 1.693074 & 6.435246 \\
\hline 39 & $\begin{array}{l}\text { Cruise/Acceleration: } \\
24 \leq \mathrm{VSP}<30,50 \leq \text { speed }\end{array}$ & 0 & 5.965447 & 7.944694 & 1.97102 & 8.029796 \\
\hline 40 & $\begin{array}{l}\text { Cruise/Acceleration: } \\
30 \leq \text { VSP, } 50 \leq \text { speed }\end{array}$ & 0 & 5.097057 & 6.474 & 1.709333 & 8.066 \\
\hline
\end{tabular}

study results on the vehicle emissions at a signalized intersection that were calculated based on Table 1 as well [18].

Obviously, the emission rates in the terminal overall are absolutely higher than at a normal signalized intersection. Further, the $\mathrm{CO}$ emission that mostly produced by an idling mode in the terminal is significantly greater. Recall the average time the vehicles cycling around terminals in Fig. 1, if partial of the vehicles can park in a nearby parking lot (normally the hourly parking lot), the emissions at terminals could be greatly reduced. 


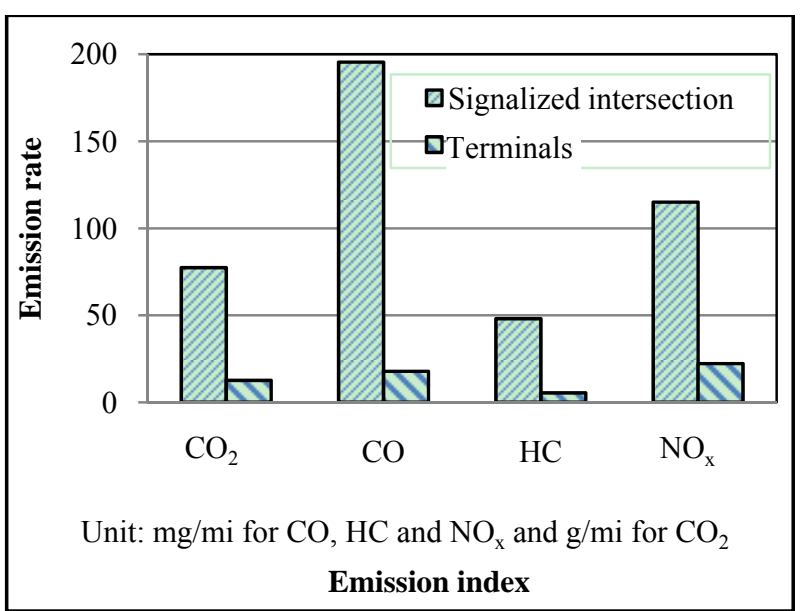

Fig. 5 Comparison of the hourly emission rates in a terminal of William P. Hobby airport in Houston and at a signalized intersection.

\section{Strategies Proposed}

In order to decrease the waiting time at airport terminals, a new management strategy is proposed to offer at least "One Hour Free Parking" at the hourly parking lot. This will be a direct way to reduce vehicle emissions at airports terminals for the total reduction in Vehicle-Miles-Traveled (VMT) and the vehicle idling duration.

\section{Conclusions}

In this research, the emissions at airport terminals from passenger-pick-up vehicles were estimated based on the geo-location information from GPS devices by a floating car method. The Drivers average cycling time around terminals was obtained from a questionnaire survey. The emissions were estimated based on the real world emission measurement database, and the operating mode bin was calculated based on the EPA new model emission MOVES. Further in-depth tests and analyses will be conducted. It is recommended to implement suitable management strategies such as the "One Hour Free Parking" policy to reduce the emissions at airports.

\section{Acknowledgements}

The authors acknowledge that this research is supported in part by Texas Southern University Seed
Grant, the Tier 1 University Transportation Center Tran LIVE, and the National Science Foundation (NSF) under grants \#1137732. The opinions, findings and conclusions or recommendations expressed in this material are those of the authors and do not necessarily reflect the views of the funding agencies.

\section{References}

[1] Qiao, F. X., Rahman, R., Li, Q., and Yu, L. 2016. "Identifying Smartphone Based Intelligent Messages for Worker's Crossing in Work Zone." Journal of Transportation Technologies 6 (2): 76-85.

[2] Li, Q., Qiao, F. X., Wang, X., and Yu, L. 2016. "Drivers Smart Advisory System Improves Driving Performance at STOP Sign Intersections." Presented at Journal of Traffic and Transportation Engineering.

[3] Qiao, F. X., Rahman, R., Li, Q., and Yu, L. 2016. "Identifying Demographical Effects on Speed Patterns in Work Zones Using Smartphone Based Audio Warning Message System." Journal of Ergonomics 6: 153. doi:10.4172/2165-7556.1000153.

[4] Li, Q., Qiao, F. X., and Yu, L. 2014. "Impacts of Vehicles to Infrastructure Communication Technologies on Vehicle Emissions." Presented at the International Conference on Environmental Science and Technology.

[5] Qiao, F. X., Li, Q., and Yu, L. 2014. "Testing Impacts of Work Zone X2V Communication System on Safety and Air Quality in Driving Simulator.” In the Proceedings of the 21st ITS World Congress, 64.

[6] Munni, J., Qiao, F. X., Li, Q., and Yu, L. 2015. "Driving Behavior and Emission Analysis at Yellow Interval with Advanced Warning Message under Foggy Weather Condition: A Simulator Test." Presented at the 56th Annual Transportation Research Forum.

[7] Li, Q., Qiao, F. X., and Yu, L. 2015. "Implications of Advanced Warning Messages on Eliminating Sun Glare Disturbances at Signalized Intersections." Presented at Journal of Traffic and Transportation Engineering.

[8] Qiao, F. X., Jia, J., Yu, L., Li, Q., and Zhai, D. 2014. "Drivers' Smart Assistance System Based on Radio Frequency Identification." Journal of Transportation Research Board 2458: 37-46.

[9] Li, Q., Qiao, F. X., and Yu, L. 2016. "Vehicle Emission Implications of Drivers Smart Advisory System for Traffic Operations in Work Zones." Journal of Air \& Waste Management $66 \quad$ (1): $87-96$. doi:10.1080/10962247.2016.1140095.

[10] Li, Q., Qiao, F. X., and Yu, L. 2015. "Clustering Pavement Roughness Based on the Impacts on Vehicle Emissions and Public Health.” Journal of Ergonomics 6 
(1): 1-4. doi:10.4172/2165-7556.1000146.

[11] Li, Q., Qiao, F. X., and Yu, L. 2015. "Implications of Wireless Communication System for Traffic Operations on Vehicle Emissions." Presented at the 107th Air \& Waste Management Association (AWMA).

[12] Lin, S. 2007. "Residential Proximity to Large Airports and Potential Health Impacts in New York State." Int. Arch. Occupy Environ. Health 81 (7): 797-804. doi:10.1007/s00420-007-0265-1.

[13] Yu, L., Li, X., and Zhuo, W. 2003. Texas Department of Transportation. Airport Related Traffic and Mobile Emission Implications report.

[14] Li, Q., Qiao, F. X., and Yu, L. 2016. "Calibrating Emission Factors for Highways Considering Pavement Roughness Information." Presented at the 2016 Air Quality Measurement Methods and Technology.
[15] Li, Q., Qiao, F. X., and Yu, L. 2016. "Estimating Vehicle Idle Emissions Based on On-Board Diagnostic II Data." Presented at the 2016 Air Quality Measurement Methods and Technology.

[16] Barth, M., Malcolm, C., Younglove, T., and Hill, N. 2001. "Recent Validation Efforts for a Comprehensive Modal Emissions Model." Journal of Transportation Research Record 1750: 13-23.

[17] Frey, H. C., and Liu, B. 2013. "Development and Evaluation of a Simplified Version of MOVES for Coupling with a Traffic Simulation Model." Presented at 91st Transportation Research Board.

[18] Li, Q., Qiao, F. X., and Yu, L. 2015. "Will Vehicle and Roadside Communications Reduce Emitted Air Pollution?" International Journal of Science and Technology 5 (1): 17-23. 